\title{
ANALISIS PERAN PEMUDA TERHADAP PEMBANGUNAN PERTANIAN LAHAN PANGAN BERKELANJUTAN DI KABUPATEN LABUHANBATU UTARA
}

\section{Ajuan Ritonga ${ }^{1 * \text { Erlina }^{2} \text { dan Supriadi }}{ }^{2}$}

1. Staf DPR komisi D Prov. Sumut.

2. Program Studi Perencanaan Pembangunan Wilayah dan Pedesaan, Sekolah Pascasarjana, USU, Medan 20155

*Corresponding author: ajuan.ritonga@ gmail.com

\begin{abstract}
The agriculture development of progressive crop land consists of three significant factors such as human resources, natural resources and appropriate technology. The method used in the research is survey, a kind of research of which data is collected from samples over population to represent all population. The type of survey used is explanatory research, a kind of research means to explain the position of variables researched and the relation between a variable and another. The population of the research was all the youths in Labuhan batu Utara being 17-30 years old. According to BPS data in 2013, there were 46,091 youths in Labuhan batu Utara. Sampling used simple sampling random method where sample taken randomly from population based on the probability frequency of all the population's members. By using the formula of Frank Lynk, it was obtained 96 sample respondents. The conclusion of the research is 1) the youths' perception to the agriculture development of progressive crop land in Labuhanbatu Utara is positive, 2) the youths' role to the agriculture development of progressive crop land in Labuhanbatu Utara is positive and 3) the effect of the youths' role as the agent of change, the agent of development and the agent of modernization is simultaneously significant to the agriculture development of progressive crop land in all the aspects- human resources, natural resources and appropriate technology. Meanwhile the variable of the agent of modernization effects positively but is not significant to the agriculture development of progressive crop land.
\end{abstract}

Keyword: youth, agriculture development, food Land Sustainable

\begin{abstract}
ABSTRAK
Pembangunan peratanian lahan pangan berkelanjutan terdiri dari tiga faktor penting yang harus diperhatikan yaitu sumberdaya manusia, sumberdaya alam dan teknologi tepat guna. Salah satu unsur sumberdaya manusia adalah pemuda. Metode yang digunakan dalam penelitian ini adalah penelitian survey yaitu penelitian yang datanya dikumpulkan dari sampel atas populasi untuk mewakili seluruh populasi. jenis penelitian yang digunakan adalah penelitian eksplanatoris. yaitu penelitian yang bermaksud menjelaskan kedudukan variabel-variabel yang diteliti serta hubungan antara satu variabel dengan variabel lain. Populasi dalam penelitian ini adalah seluruh pemuda yang ada di Kabupaten Labuhanbatu Utara yang memiliki umur 17-30 tahun. Berdasarkan data BPS tahun 2013 ada 46.091 orang. Pengambilan sampel dengan menggunakan metode simple Random sampling dimana pengambilan sampel dari populiasi secara acak berdasarkan frekuensi probabilitas semua anggota populasi. Dengan menggunakan rumus Frank Lynk diperoleh sampel sebanyak 96 orang sampel responden. Adapun kesimpulan dari penelitian ini adalah (1) Persepsi pemuda terhadap pembangunan pertanian lahan pangan
\end{abstract}


berkelanjutan di Kabupaten Labuhanbatu Utara positif, (2) Peran pemuda terhadap pembangunan pertanian lahan pangan berkelanjutan di Kabupaten Labuhanbatu Utara positif, (3) Pengaruh peran pemuda sebagai agen of change, agen of depelovment dan agen of modernization secara simultan berpengaruh positif signifikan terhadap pembangunan pertanian lahan pangan berkelanjutan dalam aspek SDM, SDA dan teknologi tepat guna. Secara parsial variabel agen of change, agen of depelovment signifikan terhadap pembangunan pertanian lahan pangan berkelanjutan dalam SDM, SDA dan teknologi tepat guna Sedangkan variabel agen of modernization berpengaruh positif namun tidak signifikan terhadap pembangunan pertanian lahan pangan berkelanjutan.

Kata Kunci : Peran Pemuda, Pembangunan Pertanian, Lahan Pangan Berkelanjutan.

\section{PENDAHULUAN}

Masa depan Bangsa Indonesia ditentukan oleh para generasi muda, kaum muda Indonesia adalah masa depan Bangsa, Karena itu setiap pemuda Indonesia, baik yang masih berstatus pelajar, mahasiswa ataupun yang sudah menyelesaikan pendidikannya merupakan faktor penting yang sangat diandalkan oleh Bangsa Indonesia dalam mewujudkan cita-cita bangsa dan juga mempertahankan kedaulatan bangsa.

Dalam upaya mewujudkan cita-cita dan mempertahankan kedaulatan bangsa ini tentu akan menghadapi banyak permasalahan, hambatan, rintangan dan bahkan ancaman yang harus dihadapi. Masalah-masalah yang harus dihadapi itu beraneka ragam. Dengan masalah-masalah yang sudah ada maupun yang akan datang, penting bagi rakyat Indonesia, terutama kaum pemuda untuk membiasakan diri dalam meningkatkan dan memperbaiki produktifitas kita berbangsa dan bernegara.

Di era globalisasi sekarang ini peran pemuda juga sangat berpengaruh terhadap bangsa. Baik itu dalam lingkup ilmu pengetahuan maupun etika. Walaupun belakangan ini Problematika pemuda terbentang di hadapan kita sekarang sangatlah kompleks, mulai dari masalah, krisis eksistensi, krisis mental hingga masalah dekadensi moral. Budaya permisif dan pragmatisme yang kian merebak membuat sebagian pemuda terjebak dalam kehidupan serba instant, hedonis, dan terlepas dari idealisme sehingga cenderung menjadi manusia yang anti sosial.Generasi muda adalah generasi harapan bangsa. Pernyataan ini akan sangat membanggakan bagi masyarakat Indonesia apabila dapat menjadi kenyataan. Akan tetapi, faktanya membuktikan bahwa generasi muda di Indonesia saat ini cenderung mengkhawatirkan perilakunya bagi kelanjutan masa depan bangsa ini. Hal ini dapat dilihat dari banyaknya kasus yang terjadi pada generasi muda antara lain kasus narkoba, kejahatan, pergaulan bebas dan lain sebagainya. Peranan pemuda dan mahasiswa tentunya masih sangat diperlukan dalam mewujudkan dan melanjutkan cita-cita bangsa ini yang telah diperjuangkan oleh para pahlawan terdahulu.

Pemuda berperan aktif sebagai kekuatan moral, kontrol sosial, dan agen perubahan dalam segala aspek pembangunan nasional. Peran aktif pemuda sebagai kekuatan moral diwujudkan dengan menumbuh kembangkan aspek etik dan moralitas dalam bertindak pada setiap dimensi kehidupan kepemudaan, memperkuat iman dan takwa serta ketahanan mental- spiritual, dan meningkatkan kesadaran hukum. Sebagai kontrol sosial diwujudkan dengan memperkuat wawasan kebangsaan,membangkitkan kesadaran atas tanggungjawab, hak, dan kewajiban sebagai warga negara, membangkitkan sikap kritis terhadap lingkungan dan penegakan hukum, meningkatkan partisipasi dalam perumusan kebijakan publik, menjamin transparansi dan akuntabilitas publik, dan memberikan kemudahan akses informasi. 
Pemuda merupakan suatu identitas dan penerus perjuangan generasi terdahulu untuk mewujukan cita-cita bangsa. Pemuda menjadi harapan dalam setiap kemajuan di dalam suatu bangsa, Pemuda dapat merubah pandangan orang terhadap suatu bangsa dan menjadi tumpuan para generasi terdahulu untuk mengembangkan suatu bangsa dengan ide-ide ataupun gagasan ilmu, wawasan yang luas, serta berdasarkan kepada nilai-nilai dan norma yang berlaku di dalam masyarakat. Kekayaan alam yang ada dinegeri ini sangat banyak jika pemuda mau dan mampu mengelolaanya maka masyarakat yang ada negara ini akan lebih sejahtera.

Indonesia di juluki negara agraris selain potensi wilayah kita dalam pertanian sangatlah baik. Tanah yang subur, berada pada iklim tropis yang sangat mendukung bagi kegiatan budidaya hampir semua jenis tanaman di dunia. Bahkan dengan campur tangan kita, tanaman mampu berbuah diluar musim yang tak banyak bisa dilakukan di negara lain. Gunung berapi aktif tersebar hampir merata disemua wilayah, menjadikan tanah kita kaya nutrisi yang diperlukan tanaman. Tapi mengapa sektor pertanian masih belum di optimalkan, sebagai contoh, untuk memenuhi kebutuhan beras di dalam negeri Indonesia harus mengimpor dari Thailand, kedelai juga kita harus mengimpor dari negara lain.

Sektor pertanian di Indonesia hingga kini masih dihadapkan pada persoalan klasik untuk dapat meningkatkan produktivitas beras nasional. Setidaknya, ada dua persoalan klasik yang dihadapi sektor pertanian. Pertama, konversi lahan (pertanian) yang setiap tahunnya mencapai 100.000 hektar. Kedua, kecenderungan perilaku generasi muda di pedesaan yang tidak lagi tertarik ikut serta dalam kegiatan pertanian padi karena dianggap tidak menarik. Persoalan itu sangat disayangkan karena faktanya hampir 90 persen rakyat Indonesia mengonsumsi beras sebagai makanan pokok sehari-hari. Tak hanya sebagai makanan pokok, beras menjadi simbol dari kesejahteraan dan kestabilan sosial di dalam masyarakat. Data Biro Pusat Statistik 2013 menyebutkan bahwa sekitar 20,4 juta orang terlibat dalam pertanian pangan. Dari kisaran tersebut, sekitar 18 juta orang kemungkinan terlibat dalam kegiatan pertanian padi.

Dalam rangka membangun pertanian yang berkelanjutan lahan merupakan sumberdaya pokok dalam usaha pertanian, terutama pada kondisi sebagian besar bidang usahanya masih bergantung pada pola pertanian berbasis lahan. Lahan merupakan sumberdaya alam yang bersifat langka karena jumlahnya tidak bertambah, tetapi kebutuhan terhadap lahan selalu meningkat. Secara nasional dalam setahun telah terjadi konversi lahan pertanian sebanyak 140 ribu hektar untuk berbagai kepentingan. Khususnya lahan sawah terjadi penurunan luas sebesar 10.000 hektar setiap tahunnya dalam dua dekade terakhir, inipun sejauh yang terdata, karena masih banyak lahan dengan luasan pada kawasan non sentra produksi padi yang luput dari perhatian tetapi terus dikonversi menjadi penggunaan di luar pertanian (Dinas Pertanian Provinsi Sumut, 2013).

Tahun 2005 - 2009 merupakan rentang waktu alih fungsi lahan sawah terbesar di sumatera utara (37,5\%). Frekuensi tertinggi adalah tanaman lahan kering palawija dan sayuran. Sedangkan untuk kelapa sawit dan bangunan merupakan frekuensi tertinggi selanjutmya. Labuhanbatu Utara merupakan salah satu Kabupaten yang berada di Provinsi Sumatera Utara. Kabupaten Labuhanbatu Utara menempati area seluas $35150 \mathrm{Ha}$, kabupaten Labuhanbatu Utara merupakan Kabupaten yang tertinggi alih fungsi lahan baku sawahnya di Provinsi Sumatera Utara, pada tahun 2011 luas lahan sawah di Kabupaten Labuhanbatu Utara sekitar 30.248 Ha sedangkan pada tahun 2012 luas lahan sawah di kabupaten Labuhanatu Utara sekitar 22.804 Ha artinya ada sekitar 7.444 Ha lahan sawah yang di alih fungsikan (Bps Provinsi Sumatera Utara, 2013).

Beberapa hal yang menjadi permasalahan sektor pertanian terkait dengan pertanahan adalah terbatasnya sumberdaya lahan yang cocok untuk kegiatan pertanian, semakin banyaknya petani gurem, tidak 
amannya status penguasaan lahan, dan cepatnya konversi lahan pertanian menjadi non pertanian. Selain faktor penyebab alih fungsi lahan pertanian yang meningkat jumlah penduduk dan taraf kehidupan menjadi isu yang hangat jika dikaitkan dengan lahan pangan berkelanjutan.

Oleh karena hal di atas, perlu dilakukan kajian sejauh mana peran pemuda dalam pembangunan pertanian berkaitan dengan lahan pangan berkelanjutan. Kajian ini diharapkan dapat memberikan gambaran pola pengembangan pertanian yang berbasis pemuda terutama di Kabupaten Labuhanbatu Utara.

\section{BAHAN DAN METODE}

Penelitian ini dilakukan di Kabupaten Labuhanbatu Utara Provinsi Sumatera Utara, waktu penelitian dilaksanakan selama 3 (tiga) bulan yakni bulan april sampai dengan juni 2015. Lokasi penelitian ditentukan secara Purposive, berdasarkan pertimbangan bahwa, Kabupaten Labuhanbatu Utara merupakan salah satu kabupaten yang ada di Provinsi Sumatera Utara dengan pengalihan lahan sawah terbesar. maka jenis penelitian yang digunakan adalah penelitian eksplanatoris. Data yang digunakan dalam penelitian ini adalah data primer dan data skunder. teknik sampling yang digunakan dalam penelitian ini adalah Simple Random Sampling. dimana Simple Random Sampling adalah metode paling dekat dengan definisi Probability Sampling. Pengambilan sampel dari populiasi secara acak berdasarkan frekuensi probabilitas semua anggota populasi. Dalam penelitian ini jumlah responden yang ditetapkan sebagai sampel sebesar 96 orang.

Adapun metode analisis yang digunakan untuk menjawab permasalahan dan hipotesis penelitian yang ada dalam penelitian ini adalah sebagai berikut:

Untuk menjawab permasalahan yang pertama yaitu bagiamana persepsi pemuda terhadap pembangunan pertanian lahan pangan berkelanjutan di Kabupaten Labuhanbatu Utara. Maka dilakukan uji deskriptif, dengan melakukan uji rata-rata. Jika nilai rata-rata jawaban responden lebih besar atau sama dengan 4 (empat), maka persepsi pemuda terhadap terhadap pembangunan pertanian lahan pangan berkelanjutan di Kabupaten Labuhanbatu Utara adalah positif.

Demikian juga dengan pertanyaan penelitian kedua, jika jawaban responden lebih besar atau sama dengan 4 (empat) berarti peran pemuda dalam pembangunan pertanian lahan pangan berkelanjutan di Kabupaten Labuhanbatu Utara positif.

Untuk melakukan pengujian terhadap hipotesis ketiga dilakukan dengan uji regresi berganda dengan model

$$
\mathrm{Y} 1,2,3=\mathrm{a}+\mathrm{b} 1 \mathrm{X} 1+\mathrm{b} 2 \mathrm{X} 2+\mathrm{b} 3 \mathrm{X} 3+\mathrm{e}
$$

Keterangan:

$\mathrm{Y}=$ Variabel dependen/terikat (nilai yang diprediksikan) dalam hal ini adalah pembangunan pertanian lahan pangan berkelanjutan.

$\mathrm{Y}_{1}=$ Sumber daya manusia

$\mathrm{Y}_{2}=$ Sumber daya alam

$\mathrm{Y}_{3}=$ Teknologi tepat guna

$\mathrm{X}_{1}=$ Peran pemuda Agent of change

$\mathrm{X}_{2}=$ Peran Pemuda Agent of develepoment

$\mathrm{X}_{3}=$ Peran pemuda Agent of modernization

$\mathrm{A}=$ Konstanta (nilai Y apabila $\mathrm{X}=0$ )

$\mathrm{b}=$ Koefisien regresi (nilai peningkatan jika bernilai positif ataupun penurunan jika bernilai negatif)

\section{HASIL DAN PEMBAHASAN}

\section{Persepsi pemuda terhadap pembangunan pertanian lahan pangan berkelanjutan.}

di Kabupaten Labuhanbatu Utara dari hasil penelitian yang dilakukan. Persepsi pemuda terhadap pembangunan pertanian lahan pangan berkelanjutan positif, hal ini dibuktikan dengan hasil wawancara langsung dengan pemuda yang ada di Kabupaten Labuhanbatu Utara. Persepsi pemuda terhadap pembangunan pertanian lahan pangan berkelanjutan meliputi aspek nilai ekonomi, kondisi lingkungan, perhatian pemerintah, peran pemuda dalam pertanian dan prestise. 
Rata-rata skor persepsi pemuda dapat dilihat pada Tabel 1 berikut ini.

Tabel 1.Skor persepsi pemuda terhadap pembangunan pertanian lahan pangan berkelanjutan

\begin{tabular}{llc}
\hline \multirow{2}{*}{ No } & \multicolumn{1}{c}{ Persepsi } & $\begin{array}{c}\text { Ratan } \\
\text { Skor }\end{array}$ \\
\hline 1 & Kondisi Lingkungan & 3,8 \\
2 & Nilai Ekonomi & 3,9 \\
3 & Perhatian Pemerintah & 3,8 \\
4 & Peran Pemuda dalam & 4,2 \\
5 & Pertanian & 3,9 \\
\hline \multicolumn{3}{l}{ Prestise } \\
Rataan Skor Semua & 3,9 \\
\hline
\end{tabular}

Sumber : Di olah dari data primer, 2015.

Interpretasi terhadap skor dari setiap variabel persepsi adalah dengan melihat skor rata-rata dan selanjutnya nilai tersebut diinterpretasikan dengan beracuan pada tabel 2 untuk menyatakan apakah seluruh variabel berada pada daerah yang telah ditentukan pada tabel.

Tabel 2. Dasar interpretasi skor item kuisioner pada variabel persepsi dalam penelitian

\begin{tabular}{ccc}
\hline No & $\begin{array}{c}\text { Nilai } \\
\text { skor }\end{array}$ & Interpretasi \\
\hline 1 & $0<\mathrm{NS} \leq 1$ & $\begin{array}{c}\text { Berada pada daerah } \\
\text { sangat negatif } \\
\text { Berada pada daerah } \\
\text { negatif }\end{array}$ \\
2 & $1<\mathrm{NS} \leq 2$ & $\begin{array}{c}\text { Berada pada daerah } \\
\text { tengah-tengah } \\
\text { Berada pada daerah } \\
\text { positif }\end{array}$ \\
4 & $3<\mathrm{NS} \leq 3$ \\
5 & $4<\mathrm{NS} \leq 5$ & $\begin{array}{c}\text { Berada pada daerah } \\
\text { sangat positif }\end{array}$ \\
\hline
\end{tabular}

Sumber : Arikunto, 1989.

Dari skor rata-rata semua variabel persepsi responden terhadap pembangunan pertanian lahan pangan berkelanjutan berada pada daerah positif. Hasil ini mengindikasikan bahwa terdapat kesepahaman bahwa sebagian besar responden memiliki persepsi akan pentingnya pembangunan pertanian lahan pangan berkelanjutan di Kabupaten Labuhanbatu Utara.

\section{Peran pemuda terhadap pembangunan pertanian lahan pangan berkelanjutan.}

Untuk mengetahui peran pemuda dalam pembangunan pertanian lahan pangan berkelanjutan di Kabupaten Labuhanbatu Utara dapat dilihat pada tabel 3 berikut ini.

Tabel 3. Skor peran pemuda dalam pembangunan pertanian lahan pangan berkelanjutan

\begin{tabular}{|c|c|c|}
\hline No & Peran pemuda & Ratan Skor \\
\hline 1 & Agent Of Change & 3,9 \\
\hline 2 & Agent Of develepoment & 3,4 \\
\hline 3 & Agent of modernization & 3,4 \\
\hline & $\begin{array}{l}\text { Rataan Skor Semua } \\
\text { Aspek }\end{array}$ & 3,6 \\
\hline
\end{tabular}

Sumber : Di olah dari data primer, 2015.

Interpretasi terhadap skor dari setiap variabel peran pemuda adalah dengan melihat skor rata-rata dan selanjutnya nilai tersebut diinterpretasikan dengan beracuan pada Tabel 3 untuk menyatakan apakah seluruh variabel berada pada daerah yang telah ditentukan pada Tabel 4 berikut ini.

Tabel 4. Dasar interpretasi skor item kuisioner pada variabel peran pemuda dalam pembangunan pertanian lahan pangan berkelanjutan.

\begin{tabular}{llll}
\hline No & Nilai skor & \multicolumn{3}{l}{ Interpretasi } \\
\hline 1 & $0<\mathrm{NS} \leq 1$ & $\begin{array}{l}\text { Berada pada } \\
\text { sangat negatif }\end{array}$ & daerah \\
2 & $1<\mathrm{NS} \leq 2$ & $\begin{array}{l}\text { Berada pada } \\
\text { negatif daerah }\end{array}$ & \\
3 & $2<\mathrm{NS} \leq 3$ & $\begin{array}{l}\text { Berada pada } \\
\text { tengah-tengah }\end{array}$ & daerah \\
4 & $3<\mathrm{NS} \leq 4$ & $\begin{array}{l}\text { Berada pada } \\
\text { positif daerah } \\
\text { Berada pada } \\
\text { sangat positif }\end{array}$ & daerah \\
5 & $4<\mathrm{NS} \leq 5$ & \\
\hline
\end{tabular}

Sumber : Arikunto, 1998.

Dari skor rata-rata semua variabel peran pemuda dalam pembangunan pertanian lahan pangan berkelanjutan berada pada daerah positif. Hasil ini mengindikasikan 
bahwa terdapat kesepahaman bahwa sebagian besar responden terhadap variabel peran pemuda sebagai Agent Of Change, Agent Of develepoment, Agent of modernization. Dengan demikian dapat dikatan bahwa secara umum variabel peran pemuda sebagai Agent

Pengaruh peran kepemudaan terhadap pembangunan pertanian berkelanjutan dalam aspek sumber daya manusia (SDM)

Uji simultan digunakan untuk mengetahui apakah variabel independen secara
Of Change, Agent Of develepoment, Agent of modernization merupakan faktor penting yang berperan dalam pembangunan pertanian lahan pangan berkelanjutan di Kabupaten Labuhanbatu Utara.

bersama-sama atau simultan mempengaruhi variabel dependen. Untuk lebih jelasnya dapat dilihat pada Tabel 5 .

Tabel 5. Hasil pengujian simultan (Uji F) pengaruh peran kepemudaan terhadap pembangunan pertanian lahan pangan berkelanjutan dalam aspek SDM.

\begin{tabular}{|c|c|c|c|c|c|c|}
\hline \multicolumn{7}{|c|}{ ANOVA $^{a}$} \\
\hline Model & & Sum of Squares & Df & Mean Square & $\mathrm{F}$ & Sig. \\
\hline 1 & Regression & 383,546 & 3 & 127,849 & 107,135 &, $000^{\mathrm{b}}$ \\
\hline a. Depe & $\begin{array}{l}\text { Residual } \\
\text { Total } \\
\text { dent Variable }\end{array}$ & $\begin{array}{l}109,787 \\
493,333\end{array}$ & $\begin{array}{l}92 \\
95\end{array}$ & 1,193 & & \\
\hline
\end{tabular}

Sumber : Di olah dari data primer, 2015.

Uji statistik secara simultan ditunjukkan oleh perbandingan nilai $\mathrm{F}$ hitung dengan $F$ tabel. Nilai $F$ tabel dengan derajat kepercayaan sebesar 95 persen, adalah sebesar 2,47. Pada Tabel 5 di atas terlihat bahwa pada persamaan, F hitung 107,135 adalah lebih besar dari pada $\mathrm{F}$ tabel. Tingkat probabilitas 0,000 . Maka dapat disimpulkan $\mathrm{P}=0,000<\alpha$ $=0,05$ yang berarti $\mathrm{Ha}$ diterima. Ini menjelaskan bahwa variabel independen (Agent of change, Agent of develepoment Agent of modernization) secara simultan signifikan dalam menjelaskan pembangunan pertanian lahan pangan berkelanjutan dalam aspek sumber daya manusia.

\section{Hasil uji parsial (Uji-t)}

Pada uji statistik secara parsial dengan nilai $\mathrm{t}$ kritis (critical value) pada $\mathrm{df}=(\mathrm{n}-\mathrm{k})$, dimana $\mathrm{n}$ adalah jumlah sampel dan $\mathrm{k}$ adalah jumlah variabel independen termasuk konstanta. Untuk menguji koefisian regresi parsial secara individu dari masing-masing variabel bebas dapat dilihat pada Tabel 6 . 
Tabel 6. Hasil pengujian parsial $(\mathrm{Uji}-\mathrm{t})$ pengaruh peran kepemudaan terhadap pembangunan pertanian lahan pangan berkelanjutan.

\begin{tabular}{|c|c|c|c|c|c|c|c|}
\hline \multirow[b]{3}{*}{ Model } & \multicolumn{4}{|c|}{ Coefficients $^{a}$} & \multirow[b]{3}{*}{ Sig. } & & \\
\hline & \multicolumn{2}{|c|}{$\begin{array}{l}\text { Unstandardized } \\
\text { Coefficients }\end{array}$} & \multirow{2}{*}{$\begin{array}{l}\text { Standardized } \\
\text { Coefficients } \\
\text { Beta }\end{array}$} & \multirow[b]{2}{*}{$\mathrm{T}$} & & \multicolumn{2}{|c|}{$\begin{array}{l}\text { Collinearity } \\
\text { Statistics }\end{array}$} \\
\hline & $\mathrm{B}$ & Std. Error & & & & Tolerance & VIF \\
\hline 1 (Constant) & $-2,576$ & 1,637 & & $-1,573$ & 119 & & \\
\hline Agent_Of_Change & ,484 & ,082 & ,422 & 5,911 &, 000 & ,474 & 2,111 \\
\hline Agent_Of_Depelopment & ,534 & ,092 & ,471 & 5,797 &, 000 & ,366 & 2,731 \\
\hline Agent_Of_Modernization & , 168 & ,103 & 098 & 1,635 & , 106 & 674 & 1,484 \\
\hline
\end{tabular}

Pada Tabel 6 hasil uji statistik t diperoleh, sebagai berikut :

1. Variabel agent of change menunjukan thitung $=5,911$ dan t-tabel 1,660 dengan tingkat probabilitas 0,000 . Dengan demikian dapat disimpulkan $\mathrm{P}=0,000<$ $\alpha=0,05$ maka hipotesis Ho di tolak dan terima hipotesis $\mathrm{Ha}$ yang menyatakan variabel agent of change berpengaruh positif signifikan terhadap pembangunan pertanian lahan pangan berkelanjutan dalam aspek sumber daya manusia.

2. Variabel agent of depeloment menunjukan t-hitung $=5,797$ dan t-tabel 1,660 dengan tingkat probabilitas 0,000. Dengan demikian dapat disimpulkan $\mathrm{P}=$ $0,000<\alpha=0,05$ maka hipotesis Ho di tolak dan terima hipotesis $\mathrm{Ha}$ yang menyatakan variabel agent of depeloment berpengaruh positif signifikan terhadap pembangunan pertanian lahan pangan berkelanjutan dalam aspek sumber daya manusia.
3. Variabel agent of modernization menunjukan t-hitung $=1,635$ dan t-tabel 1,660 dengan tingkat probabilitas 0,106 . Dengan demikian dapat disimpulkan $\mathrm{P}=$ $0,106>\alpha=0,05$ maka hipotesis Ho di terima dan hipotesis $\mathrm{Ha}$ ditolak yang menyatakan variabel agent of modernization tidak berpengaruh signifikan terhadap pembangunan pertanian lahan pangan berkelanjutan dalam aspek sumber daya manusia.

\section{Pengaruh peran kepemudaan terhadap pembangunan pertanian berkelanjutan dalam aspek sumber daya alam (SDA)}

\section{Hasil uji simultan (Uji F)}

Uji pengaruh simultan digunakan untuk mengetahui apakah variabel independen secara bersama-sama atau simultan mempengaruhi variabel dependen. Untuk lebih jelasnya dapat dilihat pada Tabel 7 .

Tabel 7. Hasil pengujian simultan (Uji F) pengaruh peran kepemudaan terhadap pembangunan pertanian lahan pangan berkelanjutan dalam aspek SDA.

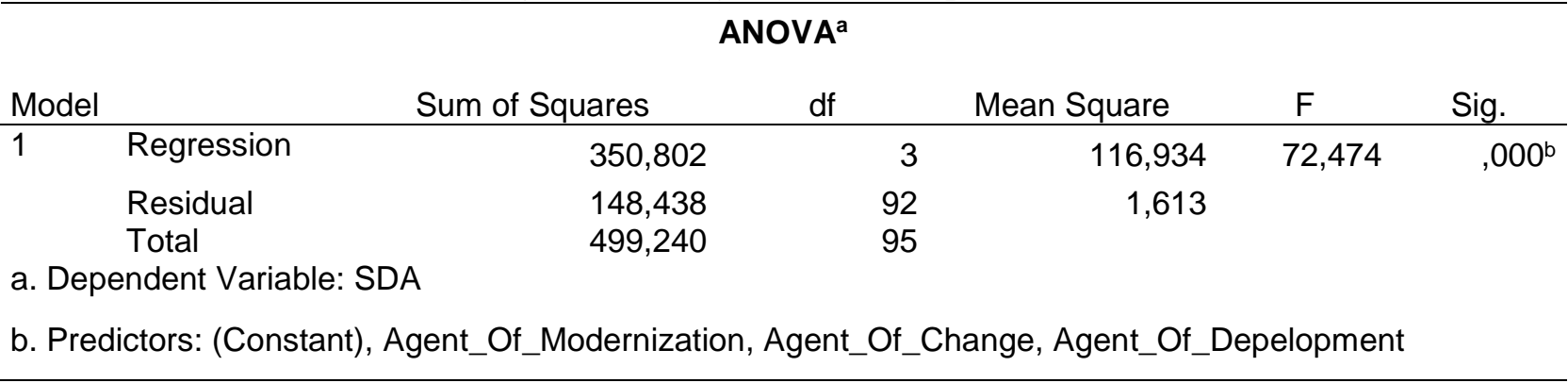

Sumber : Di olah dari data primer, 2015.

Uji statistik secara simultan ditunjukkan oleh perbandingan nilai $\mathrm{F}$ hitung dengan $\mathrm{F}$ tabel. Nilai $\mathrm{F}$ tabel dengan derajat kepercayaan sebesar 95 persen, adalah sebesar 
2,47. Pada Tabel 7 di atas terlihat bahwa pada persamaan, F hitung 72,474 adalah lebih besar dari pada $\mathrm{F}$ tabel. Tingkat probabilitas 0,000 . Maka dapat disimpulkan $\mathrm{P}=0,000<\alpha=0,05$, yang berarti Ha diterima. Ini berarti bahwa variabel independen variabel (agent of change, agent of depelovment dan agent of modernization) secara simultan signifikan dalam menjelaskan pembangunan pertanian lahan pangan berkelanjutan dalam aspek sumber daya alam.

\section{Hasil uji parsial (Uji-t)}

Pada uji statistik secara parsial dengan nilai t kritis (critical value) pada $\mathrm{df}=(\mathrm{n}-\mathrm{k})$, dimana $\mathrm{n}$ adalah jumlah sampel dan $\mathrm{k}$ adalah jumlah variabel independen termasuk konstanta. Untuk menguji koefisian regresi parsial secara individu dari masing-masing variabel bebas dapat dilihat pada Tabel 8 .

Tabel 8. Hasil pengujian parsial (Uji - t) Pengaruh peran kepemudaan terhadap pembangunan pertanian lahan pangan berkelanjutan dalam aspek SDA.

\begin{tabular}{|c|c|c|c|c|c|c|c|}
\hline \multirow[b]{3}{*}{ Model } & \multicolumn{4}{|c|}{ Coefficients $^{a}$} & \multirow[b]{3}{*}{ Sig. } & & \\
\hline & \multicolumn{2}{|c|}{$\begin{array}{l}\text { Unstandardized } \\
\text { Coefficients }\end{array}$} & \multicolumn{2}{|l|}{$\begin{array}{l}\text { Standardized } \\
\text { Coefficients }\end{array}$} & & \multicolumn{2}{|c|}{$\begin{array}{l}\text { Collinearity } \\
\text { Statistics }\end{array}$} \\
\hline & B & Std. Error & Beta & $\mathrm{T}$ & & Tolerance & VIF \\
\hline 1 (Constant) & $-3,250$ & 1,904 & & $-1,707$ & ,091 & & \\
\hline Agent Of Change & .528 & .095 & 458 & 5,543 & .000 & .474 & 2,111 \\
\hline Agent_Of_Depelopment & ,434 & ,107 & ,381 & 4,053 & 000 & ,366 & 2,731 \\
\hline Agent_Of_Modernization & , 195 & 120 & ,113 & 1,629 & ,107 & 674 & 1,484 \\
\hline
\end{tabular}

a. Dependent Variable: SDA

Sumber : Di olah dari data primer, 2015.

Pada Tabel 8 hasil uji statistik t diperoleh, sebagai berikut :

1. Variabel agent of change menunjukan $\mathrm{t}$-hitung $=5,543$ dan $\mathrm{t}$-tabel 1,660 dengan tingkat probabilitas 0,000 . Dengan demikian dapat disimpulkan $\mathrm{P}$ $=0,000<\alpha=0,05$, maka hipotesis Ho di tolak dan terima hipotesis Ha yang menyatakan variabel agent of change berpengaruh positif signifikan terhadap pembangunan pertanian lahan pangan berkelanjutan dalam aspek sumber daya alam.

2. Variabel agent of depeloment menunjukan t-hitung $=4,053$ dan $\mathrm{t}$ tabel 1,660 dengan tingkat probabilitas 0,000. Dengan demikian dapat disimpulkan $\mathrm{P}=0,000<\alpha=0,05$, maka hipotesis Ho di tolak dan terima hipotesis Ha yang menyatakan variabel agent of depeloment berpengaruh positif signifikan terhadap pembangunan pertanian lahan pangan berkelanjutan dalam aspek sumber daya alam.
3. Variabel agent of modernization menunjukan t-hitung $=1,629$ dan $\mathrm{t}$ tabel 1,660 dengan tingkat probabilitas 0,107. Dengan demikian dapat disimpulkan $\mathrm{P}=0,106>\alpha=0,05$, maka hipotesis Ho di terima dan hipotesis Ha ditolak yang menyatakan variabel agent of modernization tidak berpengaruh signifikan terhadap pembangunan pertanian lahan pangan berkelanjutan dalam aspek sumber daya alam.

\section{Pengaruh peran kepemudaan terhadap pembangunan pertanian berkelanjutan dalam aspek teknologi tepat guna.}

\section{Hasil uji simultan (Uji F)}

Uji pengaruh simultan digunakan untuk mengetahui apakah variabel independen secara bersama-sama atau simultan mempengaruhi 
variabel dependen. Untuk lebih jelasnya dapat dilihat pada Tabel 9.

Tabel 9. Hasil pengujian Simultan (Uji F) pengaruh peran kepemudaan terhadap pembangunan pertanian berkelanjutan dalam aspek teknologi tepat guna.

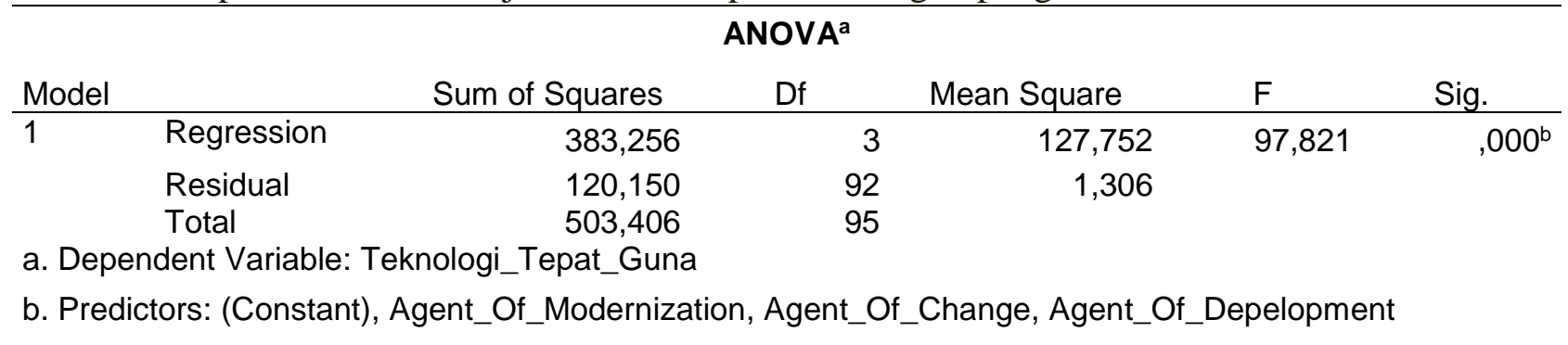

Sumber : Di olah dari data primer, 2015. Uji statistik secara simultan ditunjukkan oleh perbandingan nilai $\mathrm{F}$ hitung dengan $\mathrm{F}$ tabel. Nilai $F$ tabel dengan derajat kepercayaan sebesar 95 persen, adalah sebesar 2,47. Pada Tabel 9 di atas terlihat bahwa pada persamaan, F hitung 97,821 adalah lebih besar dari pada F tabel. Tingkat probabilitas 0,000 . Maka dapat disimpulkan $\mathrm{P}=0,000<\alpha=0,05$, yang berarti Ha diterima. Ini berarti bahwa variabel independen variabel (agent of change, agent of depelovment dan agent of modernization) secara simultan signifikan dalam menjelaskan pembangunan pertanian lahan pangan berkelanjutan dalam aspek teknologi tepat guna.

\section{Hasil uji parsial (Uji-t)}

Pada uji statistik secara parsial dengan nilai $t$ kritis (critical value) pada $\mathrm{df}=(\mathrm{n}-\mathrm{k})$, dimana $\mathrm{n}$ adalah jumlah sampel dan $\mathrm{k}$ adalah jumlah variabel independen termasuk konstanta. Untuk menguji koefisian regresi parsial secara individu dari masing-masing variabel bebas dapat dilihat pada Tabel 10.

Tabel 10. Hasil pengujian parsial (Uji t) Pengaruh peran kepemudaan terhadap pembangunan pertanian berkelanjutan dalam aspek teknologi tepat guna.

\begin{tabular}{|c|c|c|c|c|c|c|c|}
\hline \multirow[b]{3}{*}{ Model } & \multicolumn{5}{|c|}{ Coefficients $^{a}$} & & \\
\hline & \multicolumn{2}{|c|}{$\begin{array}{l}\text { Unstandardized } \\
\text { Coefficients }\end{array}$} & \multirow{2}{*}{$\begin{array}{c}\text { Standardized } \\
\text { Coefficients } \\
\text { Beta }\end{array}$} & \multirow[b]{2}{*}{$\mathrm{T}$} & \multirow[b]{2}{*}{ Sig. } & \multicolumn{2}{|c|}{$\begin{array}{c}\text { Collinearity } \\
\text { Statistics }\end{array}$} \\
\hline & $\mathrm{B}$ & Std. Error & & & & Tolerance & VIF \\
\hline 1 (Constant) & $-1,144$ & 1,713 & &,- 668 &, 506 & & \\
\hline Agent Of Change & ,465 & ,086 & ,402 & 5,430 &, 000 & ,474 & 2,111 \\
\hline Agent_Of_Depelopment &, 569 & ,096 & 497 & 5,907 & ,000 & ,366 & 2,731 \\
\hline Agent_Of_Modernization & ,123 & 108 & 071 & 1,144 & ,256 & 674 & 1,484 \\
\hline a. Dependent Variable: Tek & ogi_Tep & Guna & & & & & \\
\hline
\end{tabular}

Sumber : Di olah dari data primer, 2015.

Pada Tabel 10 hasil uji statistik t diperoleh, sebagai berikut:

1. Variabel agent of change menunjukan t-hitung $=5,403$ dan t-tabel 1,660 dengan tingkat probabilitas 0,000 . Dengan demikian dapat disimpulkan $\mathrm{P}$ $=0,000<\alpha=0,05$, maka hipotesis Ho di tolak dan terima hipotesis Ha yang menyatakan variabel agent of change berpengaruh positif signifikan terhadap pembangunan pertanian lahan pangan berkelanjutan dalam aspek teknologi tepat guna.

2. Variabel agent of depeloment menunjukan t-hitung $=5,973$ dan $\mathrm{t}$ tabel 1,660 dengan tingkat probabilitas 0,000. Dengan demikian dapat disimpulkan $\mathrm{P}=0,000<\alpha=0,05$, maka hipotesis Ho di tolak dan terima hipotesis Ha yang menyatakan variabel agent of depeloment berpengaruh 
positif signifikan terhadap pembangunan pertanian lahan pangan berkelanjutan dalam aspek teknologi tepat guna.

3. Variabel agent of modernization menunjukan t-hitung $=1,144$ dan $\mathrm{t}$ tabel 1,660 dengan tingkat probabilitas 0,107 . Dengan demikian dapat disimpulkan $\mathrm{P}=0,256>\alpha=0,05$, maka hipotesis Ho di terima dan hipotesis Ha ditolak yang menyatakan variabel agent of modernization tidak berpengaruh signifikan terhadap pembangunan pertanian lahan pangan berkelanjutan dalam aspek teknologi tepat guna.

\section{SIMPULAN}

Persepsi pemuda terhadap pembangunan pertanian lahan pangan berkelanjutan di Kabupaten Labuhanbatu Utara positif, artinya pemuda berpendapat bahwa pembangunan pertanian lahan pangan berkelanjutan di Kabupaten Labuhanbatu Utara di pandang penting. Peran pemuda terhadap pembangunan pertanian lahan pangan berkelanjutan di Kabupaten Labuhanbatu Utara positif, artinya pemuda berpendapat bahwa peran pemuda dalam pembangunan pertanian lahan pangan berkelanjutan di Kabupaten Labuhanbatu Utara di pandang penting. Pengaruh peran pemuda sebagai agent of change, agent of depelovment dan agent of modernization secara simultan berpengaruh positif signifikan terhadap pembangunan pertanian lahan pangan berkelanjutan dalam aspek sumber daya manusia, sumberdaya alam dan teknologi tepat guna. Secara parsial variabel agent of change, agen of depelovment signifikan terhadap pembangunan pertanian lahan pangan berkelanjutan dalam aspek sumber daya manusia, sumberdaya alam dan teknologi tepat guna. Sedangkan variabel agent of modernization berpengaruh positif namun tidak signifikan terhadap pembangunan pertanian lahan pangan berkelanjutan.

\section{SARAN}

Pemda Kabupaten Labuhanbatu Utara agar segera mewujudkan Peraturan Daerah tentang penetapan perlindungan lahan pertanian berkelanjutan sehingga dalam pelaksanaannya ada payung hukum yang jelas, terutama untuk kegiatan pengawasan dan pengendalian pelanggaran terhadap perlindungan lahan pertanian berkelanjutan. Perlu adanya penyuluhan pada masyarakat tentang pentingnya pengendalian konversi lahan dan sosialisasi Undang-Undang Nomor 41 Tahun 2009 tentang Perlindungan Lahan Pertanian pangan Berkelanjutan, mengingat masih banyaknya kasus konversi lahan pertanian yang terjadi. Dalam hal ini perlu adanya tindakan yang lebih pro aktif dari lembaga kepemudaan, instansi terkait seperti BPN maupun Dinas Pertanian untuk melakukan kegiatan sosialisasi. Perlu adanya pemikiran yang matang dari pemuda untuk dapat menjawab persoalan perlindungan lahan pertanian, sebab kebanyakan masyarakat hanya memiliki lahan yang sempit. Jika lahannya termasuk lahan yang dilindungi perlu diupayakan solusi untuk mengatasi permasalahan seandainya harus mengkonversi lahan untuk kebutuhan mereka.

\section{DAFTAR PUSTAKA}

Abu, Ahmadi, 1982, Psikologi Sosial, Surabaya: PT. Bina Ilmu.

Ali M, Asrori. 2006. Psikologi Remaja. Jakarta : Bumi Aksara

Arifin, Zainal. 1991. Evaluasi Instruksional Prinsip Teknik Dan Prosedur. Bandung: PT. Remaja Rosdakarya.

Azwar, Saifuddin. 2012. Sikap Manusia: Teoridan Pengukurannya. Yogyakarta : Pustaka Belajar.

Badan Pusat Statistika Daerah Kabupaten Labuhanbatu Utara dalam Angka 2013.

Badan Penyuluhan Pertanian Kabupaten Labuhanbatu Utara, 2013, Aek Kanopan 
Badan Penelitian dan Pengembangan Departemen Pertanian, 1990. Tanaman Pertanian. Departemen Pertanian RI. Jakarta

Ciptaningrum, Y. 2009. Optimasi Penggunaan Lahan Untuk Perlindungan Lahan Pertanian dan Ruang Terbuka Hijau (Studi Kasus Kawasan Perkotaan Purwokerto). Tesis. IPB. Bogor.

Djaali. 2008. Psikologi Pendidikan. Jakarta. PT Bumi Aksara.

Dinas pertanian sumatera utara, 2013. Luas lahan baku di sumatera utara. Medan

FAO.1989. Sustainable Development and Natural Resources Management. Twenty-Fifth Conference, Paper C 89/2 simp 2, Food and Agriculture Organization, Rome.

Ghozali, Imam. 2005. Aplikasi Analisis Multivariate dengan program SPSS, Semarang. Badan Penerbit Universitas Diponegoro

Hadi, S.P, 2005.Dimensi Lingkungan Perencanaan Pembangunan. Yogyakarta. Gadjah Mada University Press.

Harjono, M.R. 2005. Evaluasi Implementasi Kebijakan Pengendalian Konversi Lahan Pertanian di Kabupaten Kendal. Tesis. Undip. Semarang.

Iqbal, M. 2007. Fenomena dan Trategi Kebijakan Pemerintah Daerah dalam Pengendalian Konversi Lahan Sawah di Provinsi Bali dan Nusa tenggara Barat. Jurnal Analisis Kebijakan Pertanian.

Iqbal,M dan Sumaryanto. 2007. Strategi Pengendalian Alih Fungsi Lahan Pertanian Bertumpu pada Partisipasi Masyarakat. Jurnal Analisis Kebijakan Pertanian.

Mubyarto, 1979. Pengantar Ekonomi Pertanian, Jakarta. LP3ES.

Mosher, A.T. 1965. Menggerakan dan membangun Pertanian. Jakarta. C.V. Yasaguna.

Nur, Mohamad. 1987. Teori Tes. Surabaya: IKIP Surabaya.
Pratiwi, Rina. 2013.Pengaruh Pemahaman Materi Hak Asasi Manusia Terhadap Sikap Kemanusiaan Siswa Kelas VII Di Smp Negeri 2 Hulu Sungka Kabupaten Lampung Utara Tahun Pelajaran 2012/2013.Bandar Lampung : Universitas Lampung

Rustiadi, E. dan S. Pranoto. 2007. Agropolitan Membangun Ekonomi Perdesaan. Bogor. Crestpent Press.

Sabiham, S .2008. Manajemen Sumberdaya Lahan dan Usaha Pertanian Berkelanjutan, dalam Arsyad,S dan E. Rustiadi (Ed), Penyelamatan tanah, Air dan Lingkungan. Crestpent Press dan Yayasan Obor Indonesia.

Simatupang, P., D.K.S. Sadra, M. Syukur, E. Basuno, S. Mardianto. K. Kariyasa, dan M. Maulana. 2004. Analisis Kebijaksanaan Pembangunan Pertanian Respon terhadap Isu Aktual. Pusat Penelitian dan Pengembangan Sosial Ekonomi Pertanian, Badan Penelitian dan Pengembangan Pertanian, Departemen Pertanian. Bogor.

Soekanto, Soerjono, 2002, Teori Peranan, Jakarta, Bumi Aksara.

Sudjana. 2005. Metoda Statistika. Bandung. Tarsito.

Sugiyono. 2010. Metode Penelitian Pendidikan. Pendekatan Kuantitatif,

Kualitatif,dan $\quad R \& D$.Bandung. Alfabeta

Sugiyono. 2011. Statistika untuk Penelitian. Bandung. Alfabeta.

Sugiyono. 2006. Statistik Nonparametris Untuk Peneltian. Bandung. Alfabeta.

Suharsimi, Arikunto. 2006. Prosedur Penelitian Suatu Pendekatan. Bandung Rineka Cipta.

Suryabrata, Sumadi, 2000. Pengembangan Alat Ukur Psikologis, Yogyakarta.

Suryana, A. 2005. Pembangunan Pertanian Berkelanjutan Andalan Pembangunan Nasional. Makalah dibawakan pada Seminar Sistem Pertanian berkelanjutan untuk Mendukung Pembangunan Nasional tanggal 15 Pebruari 2005 di Universitas Sebelas Maret Solo. 
Soekartawi. 1994. Analisis Usahatani. UIPress. Jakarta

Syamson,A.B. 2011. Identifikasi Potensi Kawasan Pertanian Pangan Berkelanjutan (KP2B) Untuk menyusun RTRW Kabupaten Barru Sulawesi Selatan. Tesis. IPB. Bogor.

UU No.41 Tahun 2009 tentang Perlindungan Lahan Pertanian Berkelanjutan.

World Commission on Environment and Development. 1987. Our Common Future (Hari Depan Kita Bersama, diterjemahkan oleh Sumantri, B). PT.Gramedia. Jakarta. 